\title{
The Effect of Selfies on Cosmetic Surgery
}

\author{
Mohammed Alkarzae ${ }^{1}$, Badi Aldosari', Lama Alalula², Reham Almuhaya ${ }^{1}$, Ibrahim Alawadh ${ }^{1}$ \\ 1 Division of Facial Plastic Surgery, Department of Otolaryngology-Head and Neck Surgery, King Saud University, Riyadh, Saudi Arabia \\ 2 College of Medicine, King Saud bin Abdulaziz University, Riyadh, Saudi Arabia \\ Mohammed Alkarzae, ORCID: 0000-0002-3958-7684 \\ Badi Aldosari, ORCID: 0000-0001-9865-3795 \\ Lama Alalola, ORCID: 0000-0003-3175-2101 \\ Reham Almuhaya, ORCID: 0000-0002-3955-6976 \\ Ibrahim Alawadh, ORCID: 0000-0002-7415-7778
}

\begin{abstract}
Objective: Objectives: The present study aimed to evaluate how selfies (self-photographs) are related to cosmetic surgery.
\end{abstract}

Methods: This is a prospective, observational study performed using a self-administered survey. An online questionnaire was distributed through social media to a random sample of 653 individuals from Saudi Arabia aged 18 to 65 years (mean $29.4 \pm 10.9$ years). $25.1 \%$ of respondents were male (164 men), $74.9 \%$ were female ( 489 women).

Results: The majority of respondents were satisfied by their appearance in the selfie. $5.8 \%$ of respondents stated they had had a cosmetic procedure as a result of self-photography. The procedures involved were: lip fillers, botox, rhinoplasty, cheek fillers, chin implant, scar revision and face-lift. A further $37.8 \%$ of respondents expressed a wish to undergo a cosmetic procedure (rhinoplasty, lip fillers, chin implant, scar revision, cheek fillers, botox or facelift) due to selfies. 134 respondents expressed dissatisfaction with their appearance in selfies, 47 of whom $(35.1 \%)$ expressed an interest in a cosmetic procedure. $46 \%$ of those who believed selfies reveal their deformities also wished to have a corrective procedure. Concerning their preferred type of procedure, women chose rhinoplasty, lip fillers, cheek fillers, anti-aging botox, face-lifts and chin implants more often than men.

Conclusion: Improvements to body-image through cosmetic surgery outcomes should improve body image and thereby promote self-esteem and socialization. The selfie may underlie the increase in demand for cosmetic procedures and the number of such procedures subsequently undertaken.

Keywords: Photographs, self, social media, cosmetic techniques. 


\section{Introduction}

A selfie is a photographic self-portrait, usually taken using a mobile telephone camera. It has become a significant photographic genre and is now a key component in daily living for many individuals. Such selfies are frequently posted to social media platforms, where their prominence has led to heightened awareness by the subjects of their appearance. This, in turn, feeds into higher demand for cosmetic surgery aiming to enhance how the subject appears in future selfies.

Scholars have identified an effect known as the "Facebook Facelift", referring to the increasing tendency of young adults to pursue cosmetic surgical intervention. Such a phenomenon is indicative of the influence social media exert upon a perception of personal appearance. ${ }^{[1]}$

Taking a self-portrait is, nonetheless, not the sole way in which a subject may find him or herself photographically portrayed in an unappealing way online. The ubiquity of cellphone cameras, many of which can capture images at high resolution, means that images taken at casual social events may be reproduced on numerous social media feeds and seen by high numbers of online visitors, even if such images reveal details of imperfect appearance that those portrayed might have preferred not to be highlighted. ${ }^{[1]}$

The psychological impact on the subject of a photographic image obtained unexpectedly differs considerably from that of a posed image of a prepared subject, and may induce more acute feelings of shame when placed online. Such a psychological impact contributes to the rising demand observed by many practitioners for cosmetic procedures, the aim of which is to enhance personal appearance for photographs to be used as a social media profile. Irrespective of an individual's interest or otherwise in particular social media platforms, a significant pressure to have a pleasing appearance is frequently felt by individuals both in the real world and virtually. Cosmetic enhancements may allow individuals to be relieved of anxiety about their appearance, whatever the circumstances of social media exposure. ${ }^{[1]}$

This research was therefore undertaken given the paucity of existing scholarly literature on the way selfies influence the decision to undergo cosmetic surgery.

\section{Materials and Methods}

This was a prospective, observational study performed using a self-administered questionnaire developed specifically for the research project by using the SurveyMonkey website. Participants were selected randomly from the general population of Saudi Arabia. An online questionnaire was distributed randomly through social media and websites. Details of the questionnaire can be found in Appendix 1 . The present study was approved by the Institutional Review Board of King Saud University (E-19-3661).

\section{Subjects}

The research used a convenience sampling technique. An online questionnaire was distributed through social media to a random sample of 653 individuals aged 18 to 65 years (mean $29.4 \pm 10.9$ years). $25.1 \%$ of the respondents were male (164 men), $74.9 \%$ female (489 women).

The questionnaire was developed in consultation with cosmetic practitioners and was pre-tested for statistical rigor. Some improvements were suggested at that stage. A pilot study involving 20 respondents established the comprehensibility of the survey for general use. There were 653 participants in the survey. In the results section, a total of responders for that question can be seen in the Tables. Respondents younger than 18 years old were excluded from the study.

\section{Questionnaire (for further details, see Appendix 1)}

1-Demographics: Respondents were asked to provide information on the following: nationality, sex, age, marital status, highest educational qualification obtained, occupation and average monthly income.

2-Personal experience: Respondents were offered a binary choice $(1=$ Yes, $2=\mathrm{No})$ to indicate if they had previously considered undergoing any cosmetic procedure because of selfies, and, if so, which interventions they had considered. Any previous cosmetic procedure because of selfies was asked about, including the nature of the procedure itself.

3-Introductory questions: Respondents indicated yes or no to use of social media and taking selfies. The questions then covered how often selfies were made, which view the respondents preferred to use and whether or not they used a photographic filter. The survey also captured psychosocial and interpersonal interaction data. For these questions, a Likert scale was used with a single response on a fivepoint scale corresponding to: strongly disagree, disagree, neutral, agree and strongly agree.

4-Measures: The degree of intrest in having a cosmetic 
procedure was gauged on a 7 point scale, the extremes of which were 1 (indicating absence of interest) to 7 (indicating a very high level of interest). The respondents' satisfaction with their own appearance, both in general and in selfies, was assessed by asking them to choose a point on a 7 point scale ranging from 1 (extreme dissatisfaction) through to 7 (perfect satisfaction).

\section{Statistical analysis}

The SPSS for Windows 16.0 (SPSS, INC, an IBM Company, Chicago, Illinois) software application was used to generate descriptive statistics and to perform the Chi-square test.

A p-value below 0.05 was defined as indicating statistical significance.

\section{Results}

$59.7 \%$ of respondents reported being unmarried, whilst $35.8 \%$ reported being married. $71.4 \%$ of the sample claimed education at the level of a Bachelor's degree. $18.2 \%$ described their highest educational achievement as high school.

642 respondents $(98.3 \%$ ) admitted to social media use. When asked which platforms they used, the following picture emerged: WhatsApp: 585 (91.1\%), Snapchat: 551 (85.8\%), Twitter: 503 (78.3\%), Instagram: 422 (65.7\%), Facebook: 58 (9\%), Others: 22 (3.4\%).

610 respondents $(93.4 \%)$ stated they take selfies.

Frequency of selfie taking:

- Once a month=263 (43.1\%)

- Once a week=140 (23\%)

- More than once a week=137 (22.4\%)

- Once a day=17 $(2.8 \%)$

- More than once a day=53 (8.7\%)
Whilst taking a selfie, respondents' preferences were:

- Front view=379 (62.1\%)

- Side view=231 (37.9\%)

Use of photographic filter for selfie:

- Yes=292 (47.9\%)

- $\mathrm{No}=81(13.3 \%)$

- Sometimes=237 $(38.8 \%)$

How respondents viewed the resulting images is shown in Table 1. In summary, the key findings were as follows:

- "Shows my deformities". $40.3 \%$ felt neutral about this statement, whilst $24.2 \%$ agreed with the statement.

- "I face mocking by others because of my pictures". $45.0 \%$ strongly disagreed, whilst $14.2 \%$ were neutral

- "I take many pictures and chose the best one before posting". $40.0 \%$ agreed with this statement and $26.6 \%$ strongly agreed.

How the respondents thought about their appearance is listed in Table 2. To summarize: $25.0 \%$ were "perfectly satisfied" and 25.4\% "very satisfied" with their appearance. $20.4 \%$ were "perfectly satisfied" and $19.8 \%$ had a neutral view with regard to their appearance in selfies.

$38(5.8 \%)$ respondents claimed they had already undergone a cosmetic procedure because of selfies:

- Rhinoplasty=18 (2.8\%)

- Lip fillers=30 (4.6\%)

- Cheek fillers=17 (2.6\%)

- Botox $=21(3.2 \%)$

- Facelift=3 (0.5\%)

\section{Table 1. Respondents' thoughts about selfies.}

\begin{tabular}{|c|c|c|c|c|c|c|}
\hline Questions & $\begin{array}{c}\text { Strongly } \\
\text { disagree } \\
(n-\%)\end{array}$ & $\begin{array}{l}\text { Disagree } \\
(\mathrm{n}-\%)\end{array}$ & $\begin{array}{c}\text { Neutral } \\
(\mathrm{n}-\%)\end{array}$ & $\begin{array}{l}\text { Agree } \\
(n-\%)\end{array}$ & $\begin{array}{c}\text { Strongly } \\
\text { agree } \\
(\mathrm{n}-\%)\end{array}$ & $\begin{array}{l}\text { No response } \\
(\mathrm{n}-\%)\end{array}$ \\
\hline Selfies shows my deformities & $43(6.6 \%)$ & $121(18.5 \%)$ & $263(40.3 \%)$ & $\begin{array}{c}158 \\
(24.2 \%)\end{array}$ & $54(8.3 \%)$ & $14(2.1 \%)$ \\
\hline I face mocking by others because of my pictures & $\begin{array}{c}294 \\
(45.0 \%)\end{array}$ & $\begin{array}{c}207 \\
(31.7 \%)\end{array}$ & $\begin{array}{c}93 \\
(14.2 \%)\end{array}$ & $\begin{array}{c}38 \\
(5.8 \%)\end{array}$ & $\begin{array}{c}6 \\
(0.9 \%)\end{array}$ & $\begin{array}{c}15 \\
(2.3 \%)\end{array}$ \\
\hline $\begin{array}{l}\text { I take many pictures and chose the best one } \\
\text { before posting }\end{array}$ & $\begin{array}{c}47 \\
(7.2 \%)\end{array}$ & $\begin{array}{c}60 \\
(9.2 \%)\end{array}$ & $\begin{array}{c}97 \\
(14.9 \%)\end{array}$ & $\begin{array}{c}261 \\
(40.0 \%)\end{array}$ & $\begin{array}{c}174 \\
(26.6 \%)\end{array}$ & $\begin{array}{c}14 \\
(2.1 \%)\end{array}$ \\
\hline
\end{tabular}




\begin{tabular}{|c|c|c|c|c|c|c|c|c|}
\hline Questions & $\begin{array}{l}\text { Extremely } \\
\text { dissatisfied }\end{array}$ & $\begin{array}{c}\text { Very } \\
\text { dissatisfied }\end{array}$ & Dissatisfied & Neutral & Satisfied & $\begin{array}{c}\text { Very } \\
\text { satisfied }\end{array}$ & $\begin{array}{l}\text { Perfectly } \\
\text { satisfied }\end{array}$ & $\begin{array}{c}\text { No } \\
\text { response }\end{array}$ \\
\hline $\begin{array}{l}\text { Are you satisfied with } \\
\text { your appearance? }\end{array}$ & $\begin{array}{c}12 \\
(1.8 \%)\end{array}$ & $\begin{array}{c}15 \\
(2.3 \%)\end{array}$ & $\begin{array}{c}45 \\
(6.9 \%)\end{array}$ & $\begin{array}{c}92 \\
(14.1 \%)\end{array}$ & $\begin{array}{c}150 \\
(23.0 \%)\end{array}$ & $\begin{array}{c}166 \\
(25.4 \%)\end{array}$ & $\begin{array}{c}163 \\
(25.0 \%)\end{array}$ & $\begin{array}{c}10 \\
(1.5 \%)\end{array}$ \\
\hline $\begin{array}{l}\text { Are you satisfied with } \\
\text { your appearance in } \\
\text { selfies? }\end{array}$ & $\begin{array}{c}25 \\
(3.8 \%)\end{array}$ & $\begin{array}{c}35 \\
(5.4 \%)\end{array}$ & $\begin{array}{c}86 \\
(13.2)\end{array}$ & $\begin{array}{c}129 \\
(19.8 \%)\end{array}$ & $\begin{array}{c}117 \\
(17.9 \%)\end{array}$ & $\begin{array}{c}105 \\
(16.1 \%)\end{array}$ & $\begin{array}{c}133 \\
(20.4 \%)\end{array}$ & $\begin{array}{c}23 \\
(3.5 \%)\end{array}$ \\
\hline
\end{tabular}

- Chin implant=7 (1.1\%)

- Scar revision=6 $(0.9 \%)$

When asked about wishes to undergo cosmetic surgery resulting from selfies, $247(37.8 \%)$ respondents stated a willingness to do so, with the following procedures those considered:

- Rhinoplasty=155 (23.7\%)

- Lip fillers=92 (14.1\%)

- Cheek fillers=39 (6.0\%)

- Botox $=38(5.8 \%)$

- Facelift $=36(5.5 \%)$

- Chin implant=55 (8.4\%)

- Scar revision=43 $(6.6 \%)$

Respondents' satisfaction with selfie and interest in undergoing cosmetic surgery are shown in Table 3. 450 respondents provided a response, of which $316(70.2 \%)$ indicated satisfaction with their selfie. From this group, 244 respondents $(77.2 \%)$ had no interest in undergoing cosmetic surgery and 72 respondents $(22.8 \%)$ had interest in undergoing cosmetic surgery. 134 respondents expressed dissatisfaction with their appearance on selfie, but only 47 $(35.1 \%)$ expressed a desire to undergo cosmetic surgery $\left(\chi^{2}=7.3067 ; p=0.007\right)$.

Table 3. Satisfaction with selfie and respondents' interest in undergoing cosmetic surgery.

$\begin{array}{llll}\text { Satisfaction } & \text { Interested } & \text { Not interested } & \text { Total } \\ \text { Satisfied } & 72(22.8 \%) & 244(77.2 \%) & 316 \\ \text { Not satisfied } & 47(35.1 \%) & 87(64.9 \%) & 134 \\ \text { Total } & 119(26.4 \%) & 331(73.6 \%) & 450\end{array}$

Interest in undergoing cosmetic surgery and selfies showing deformities, mocking of facial appearance by others, and taking many pictures were shown in Table 4 . Amongst those who felt that selfies revealed their deformities, the percentage expressing an interest in cosmetic surgery ( 23 respondents, $46.0 \%$ ) was higher than in those who did not feel such deformities were shown (70 respondents, $18.9 \%)(\mathrm{p}<0.001)$. See Table 4.

The percentage of respondents who had experienced mockery because of pictures and expressed an interest in undergoing cosmetic surgery was not different at the level of statistical significance from those with an interest in cosmetic surgery for themselves who had not experienced such mockery $(\mathrm{p}=0.751)$ (Table 4).

Some 84 respondents overall expressed an interest in undergoing cosmetic surgery. Those who took many pictures before deciding which to post were more likely to be in this group than those who did not, a result that was statistically significant $(\mathrm{p}<0.001)$. See Table 4 .

Response to the interest in undergoing cosmetic procedure (yes or no) according to the sex was shown in Table 5 . Women were more likely than men to express a preference for rhinoplasty, lip fillers, cheek fillers, anti-aging botox, facelift or chin implant $(\mathrm{p}<0.05)$. For scar revision, there was no difference between males and females $(\mathrm{p}>0.05)(\mathrm{Ta}-$ ble 5).

\section{Discussion}

Perceptions of the selfie may lead to an emphasis on congenital anomalies and have effects on self-confidence. ${ }^{[2]}$ People had self-identity perception before selfies and this topic may affect self-perception apart from selfies. However, self-identity perception is out of this study design.

Saudi Arabian society has been swift to absorb such developments in digital photography, mobile accessibility 
Table 4. Interest in undergoing cosmetic surgery and selfies showing deformities, mocking of facial appearance by others, and taking many pictures.

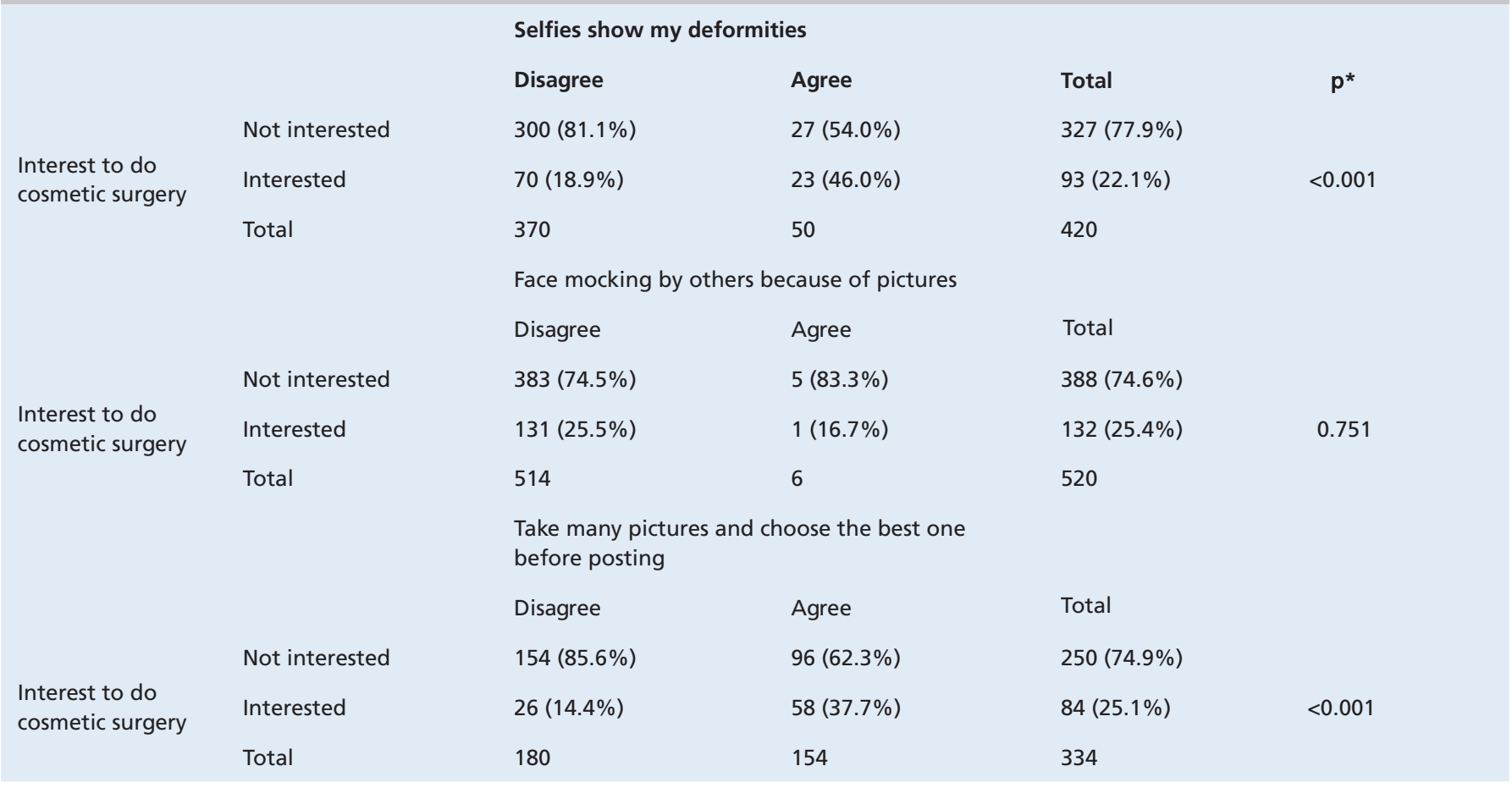

${ }^{*} p$ value shows the results of Chi-square test

\begin{tabular}{|c|c|c|c|c|}
\hline $\begin{array}{l}\text { Cosmetic } \\
\text { procedures }\end{array}$ & Responses & $\begin{array}{l}\text { Males } \\
(n=164)\end{array}$ & $\begin{array}{l}\text { Females } \\
(n=489)\end{array}$ & p \\
\hline \multirow{2}{*}{ Rhinoplasty } & Yes & $26(15.9 \%)$ & $129(26.4 \%)$ & \multirow{2}{*}{0.008} \\
\hline & No & $138(84.1 \%)$ & $360(73.6 \%)$ & \\
\hline \multirow{2}{*}{ Lip fillers } & Yes & 0 & $92(18.8 \%)$ & \multirow{2}{*}{$<0.001$} \\
\hline & No & $164(100 \%)$ & $397(81.2 \%)$ & \\
\hline \multirow{2}{*}{$\begin{array}{l}\text { Cheek } \\
\text { fillers }\end{array}$} & Yes & $1(0.6 \%)$ & $38(7.8 \%)$ & \multirow{2}{*}{0.001} \\
\hline & No & $163(99.4 \%)$ & $451(922 \%)$ & \\
\hline \multirow{2}{*}{$\begin{array}{l}\text { Botox for } \\
\text { aging }\end{array}$} & Yes & $4(2.4 \%)$ & $34(7.0 \%)$ & \multirow{2}{*}{0.033} \\
\hline & No & $160(97.6 \%)$ & 455 (93.0\%) & \\
\hline \multirow{2}{*}{ Facelift } & Yes & $4(2.4 \%)$ & $32(6.5 \%)$ & \multirow{2}{*}{0.048} \\
\hline & No & $160(97.6 \%)$ & 457 (93.5\%) & \\
\hline \multirow{2}{*}{$\begin{array}{l}\text { Chin } \\
\text { implant }\end{array}$} & Yes & $5(3.0 \%)$ & $50(10.2 \%)$ & \multirow[b]{2}{*}{0.005} \\
\hline & No & $159(97.0 \%)$ & $439(89.8 \%)$ & \\
\hline \multirow{2}{*}{$\begin{array}{l}\text { Scar } \\
\text { revision }\end{array}$} & Yes & $6(3.7 \%)$ & $37(7.6 \%)$ & \multirow{2}{*}{0.101} \\
\hline & No & $158(96.3 \%)$ & 452 (92.4\%) & \\
\hline
\end{tabular}

${ }^{*} p$ value shows the results of Chi-square test and the growth of social media. $98.3 \%$ of questionnaire respondents report their use of social media. The following were the usual social media platforms: Whatsapp, Snapchat, Twitter, Instagram, Facebook and others. 93.4\% of the participants admit to taking selfies. The frequency of taking a selfie was once a month as a most given response. Selfies may involve the front view mostly or the side view as a secondly given response; $44.7 \%$ regularly use a photographic filter, whilst $36.3 \%$ sometimes do so. The majority of respondents indicated satisfaction with their appearance in selfies.

In the present study, $5.8 \%$ of respondents indicated they had already undergone a variety of cosmetic procedures because of selfies: lip fillers, Botox, rhinoplasty, cheek fillers, chin implant, scar revision and facelift were the procedures stated to have been undergone.

The present study is in line with previous research on the willingness of males and females to contemplate cosmetic surgery, showing that a higher proportion of women (typically 85\%) contemplate such an action than men 
(somewhat below 25\%). We had a preponderance of single people in our sample. Alharethy ${ }^{[3]}$ researched the demography of patients in Saudi Arabia presenting for cosmetic procedures and found $45.2 \%$ were unmarried. Moreover, cosmetic surgery was found to be linked to eligibility for marriage. ${ }^{[4]}$

In the present study, a greater willingness to submit to cosmetic procedures was apparent amongst respondents below the age of 40 . This age profile confirms the findings of earlier research that cosmetic surgery in Saudi Arabia was most common in patients aged between 20 and $40 .{ }^{[4]}$

$37.8 \%$ of respondents in the present study expressed a wish to undergo a cosmetic procedure (rhinoplasty (23.7\%), lip fillers (14.1\%), chin implant (8.4\%), scar revision $(6.6 \%)$, cheek fillers $(6.0 \%)$, botox $(5.8 \%)$ or face-lift $(5.5 \%)$ due to selfies. According to our results, the most desired cosmetic procedures about wishes to undergo cosmetic procedures resulting from selfies were rhinoplasties.

134 respondents expressed dissatisfaction with their appearance in selfies, 47 of whom (35.1\%) expressed an interest in a cosmetic procedure. 316 respondents indicated satisfaction with their selfies, 72 of whom (22.8\%) expressed an interest in a cosmetic procedure. Our research has shown that selfie photography tends to highlight the deformity of the face and that a correlation exists between perceiving a deformity and seeking a cosmetic correction. Amongst those who felt that selfies revealed their deformities, the percentage expressing an interest in cosmetic surgery ( 23 respondents, $46.0 \%$ ) was higher than in those who did not feel such deformities were shown (70 respondents, $18.9 \%)$. Ward et al ${ }^{[5]}$ detail what they term the "selfie effect" whereby nasal foreshortening occurs in close-up photographs. Such an effect may contribute to the increase in desire for cosmetic procedures found amongst selfie-takers.

A study from the United States indicated that taking multiple selfies before selecting which to post on social media platforms was commonplace. ${ }^{[6]}$ The present study's findings are consistent with that study, insofar as $40 \%$ of respondents admitted to such behavior. Our study, however, went on to find a correlation between multiple selfie-taking and raised interest in undergoing cosmetic procedures.

The majority of patients between the ages of 16 and 36 attending a cosmetic surgery clinic bring selfies to consultations in order to illustrate where they feel the deformity is seen. They may take pictures from various angles, on occasion even finding a particular angle at which they are satisfied with their appearance. Often, however, the angle with which they are most satisfied does in fact lead to nasal distortion. ${ }^{[7]}$

"Selfie-generation" refers to the phenomenon of continual sharing of self-photography amongst younger individuals. Compared to before the advent of social media, the frequency with which people now encounter their photographic likeness is hundreds or thousands of times increased, it is estimated. ${ }^{[8]}$ Our research found a clear link between perceiving deformity on selfies or taking multiple selfies and having an increased level of interest in undergoing cosmetic surgery. $46 \%$ of those who perceived a deformity had a wish for surgical correction.

Individuals whose interest in selfies and social media is very powerful expend large amounts of time and effort attempting to achieve a pleasing photographic result. Whilst such photographic techniques cannot physically alter deficiencies in a person's appearance, such as a lopsided smile, particular applications may offer an idealized view of how a person might appear. Exposure to such apps is raised amongst heavy social media users. Since there are no alternatives to cosmetic surgery as a way to realize a different version of one's appearance in real life, cosmetic surgery consultations are becoming more widely sought after. ${ }^{[8]}$

According to the published research available, the following are the most frequently undertaken surgical procedures in females: facelift and rhinoplasty, ablative skin resurfacing and blepharoplasty. The average number of each for a surgeon to perform annually was 37, 37, 36 and 34, respectively. In 2013, it was reported, the following procedures were the most performed: anti-aging botox, filler placement, superficial peeling (i.e. micro-dermabrasion) and non-ablative resurfacing, with surgeons carrying out $348,187,119$ and 106 of each, respectively. ${ }^{[9,10]}$

The motivation to go through with a cosmetic procedure seems to be strongly linked to dissatisfaction with the current gap between wished-for and actual appearance, but also to a wish to be able to take even more attractive selfies in the future. Alarm has been expressed about this tendency, one report indicating, "This is an alarming trend because those filtered selfies often present an unattainable look and are blurring the line of reality and fantasy for these patients." $[11]$

Wang et al ${ }^{[12]}$ explored the relationships between self-esteem, body satisfaction and the posting of selfies in a group of Chinese female undergraduates. As with the 
present study, the researchers concluded that a firm association exists between satisfaction with one's bodily appearance and selfie-posting behavior. ${ }^{[14]}$

\section{Conclusion}

Selfies are commonplace and strongly linked to social media posting. Most of the respondents in our survey preferred to take frontal shots and employ a photographic filter. This research confirms the thesis that dissatisfaction with appearance as revealed in selfies has a demonstrable effect on cosmetic surgery-seeking behavior. If such surgery leads to a better self-image, it has the potential to improve socialization.

\section{Acknowledgement: None}

Ethics Committee Approval: Ethical approval was ob- tained from the Institutional Review Board of the King Saud University (E-19-3661).

Informed Consent: Informed consent was obtained from all individual participants included in the study.

Author Contributions: Designing the study - M.A., B.A., N.B.M., C.M.; Collecting the data - M.A., B.A., L.A., R.A., I.A.; Analyzing the data - B.A., R.A., I.A.; Writing the manuscript - M.A., N.B.M.; Confirming the accuracy of the data and the analyses - M.A., B.A., L.A. N.B.M., C.M.

Conflict of Interest: The authors have no conflicts of interest to declare.

Financial Disclosure: The authors declare that no financial support was received for this paper.

\section{Appendix 1-Questionnaire}

1. Nationality:

a- Saudi

b- Non-Saudi

2. Gender:

a- Female

b- Male

3. Age:

4. Marital status:

a- Single

b- Married

c- Divorced

d- Widowed

\section{Education level:}
a- Illiterate
b- Elementary school
c- Middle school
d- High school
e- Bachelor's degree
f- Master's degree
g- PhD 
6. Career field:

a- Educational

b- Military

c- Health care

d- Business

e- Engineering

f- Aviation

g- None

7. Monthly income in Saudi Riyals:

8. Do you use social networks?

a- Yes

b- No

9. Which of the following social networks do you use?

a- WhatsApp

b- Snapchat

c- Twitter

d- Instagram

e- Facebook

f- Others:

10. Do you take selfies?

a- Yes

b- No

11. How frequent do you take selfies?

a- Once a month

b- Once a week

c- More than once a week

d- Once a day

e- More than once a day

12. Which side do you prefer when taking a selfie?

a- Frontal view

b- Side view

13. Do you use filters when taking a selfie?

a- Yes

b- No

c- Sometimes

14. Selfies:

a- Show my deformities

b- I face mocking by others because of selfies

c- I take many selfies and choose the best one before posting 
15. On a scale of 1 to 7 , how satisfied are you with your general appearance?

Not Satisfied

I $\cdot \frac{7}{3} \cdot \frac{7}{4} \cdot \frac{7}{7}$
. Totally satisfied

16. On a scale of 1 to 7 , how satisfied are you with your appearance in selfies?

Not Satisfied

I $\cdot \frac{}{2} \cdot \frac{}{3} \cdot \frac{}{6} \cdot \frac{}{7} \cdot$ Totally satisfied

17. Have you ever undergone cosmetic surgery because of selfies?

a- Yes

b- No

18. If yes, what was the cosmetic surgery you underwent?

a- Rhinoplasty

b- Lip fillers

c- Cheek fillers

d- Chin fillers

e- Botox to remove wrinkles

f- Facelift

g- Scar removal

h- Others

19. Do you want to have a cosmetic procedure because of selfies?

a- Yes

b- No

20. If yes, what is the cosmetic procedure you are willing to have?

a- Rhinoplasty

b- Lip fillers

c- Cheek fillers

d- Chin fillers

e- Botox to remove wrinkles

f- Facelift

g-Scar removal

h- Others

On a scale of 1 to 7 , what is your interest level in having a cosmetic procedure?

Not Satisfied

I $\cdot \frac{}{2} \cdot \frac{}{3} \cdot \frac{}{4} \cdot \frac{}{6} \cdot \frac{}{7}$. Totally satisfied




\section{References}

1. Davis GD. Are "Selfies" Leading to More Cosmetic Surgery Procedures? Realself [Accessed online at January 12, 2019]. Available from: https:// www.realself.com/article/selfies-leading-more-cosmetic-surgery-procedures.

2. Berros P, Armstrong BK, Foti P, Mancini R. Cosmetic Adolescent Filler: An Innovative Treatment of the "Selfie" Complex. Ophthalmic Plast Reconstr Surg 2018;34:366-8.

3. Schlessinger J, Schlessinger D, Schlessinger B. Prospective demographic study of cosmetic surgery patients. J Clin Aesthet Dermatol 2010;3:305.

4. Alharethy SE. Trends and demographic characteristics of Saudi cosmetic surgery patients. Saudi Med J 2017;38:738-41.

5. Ward B, Ward M, Fried O, Paskhover B. Nasal Distortion in Short-Distance Photographs: The Selfie Effect. JAMA Facial Plast Surg 2018;20:333-5.

6. Ridgway JL, Clayton RB. Instagram Unfiltered: Exploring Associations of Body Image Satisfaction, Instagram \#Selfie Posting, and Negative Romantic Relationship Outcomes. Cyberpsychol Behav Soc Netw 2016;19:2-7.

7. Kozlowska H. A picture-perfect nose job: how the selfie is boosting demand for plastic surgery [cited 2014 November 30]. Available from: http://qz.com/303917/a-picture-perfect-nose-jobhow-the-selfie-is-boosting-demand-for-plastic-surgery/.
8. Plastic pictures: how is the 'selfie generation' changing cosmetic surgery? [cited 2018 October 9]. Available from: https://www.medicaldevice-network.com/comment/plastic-pictures-selfie-generation-changingcosmetic-surgery/.

9. Özgür E, Muluk NB, Cingi C. Is Selfie a New Cause of Increasing Rhinoplasties? Facial Plast Surg 2017;33:423-7.

10. Annual AAFPRS Survey Finds. 'Selfie' Trend Increases Demand for Facial Plastic Surgery: Survey Shows Increase in Cosmetic Procedures in the Under 30 Set. Annual AAFPRS Survey, PR Newswire Association LLC, New York [cited 2014 March 11]. Available from https://www.prnewswire.com/news-releases/annual-aafprs-surveyfinds-self-ie-trend-increases-demand-for-facial-plasticsurgery-249409811.html.

11. Rajanala S, Maymone MBC, Vashi NA. Selfies-Living in the Era of Filtered Photographs. JAMA Facial Plast Surg 2018;20:443-4.

12. Wang Y, Wang X, Liu H, Xie X, Wang P, Lei L. Selfie posting and selfes-teem among young adult women: A mediation model of positive feedback and body satisfaction. J Health Psychol 2018 Jul 1:1359105318787624.

13. Stern C. Half of women take six selfies or more before finding one they like [cited 2018 January 9]. https://www.dailymail.co.uk/femail/article-5248413/Half-women-6-SELFIES-right-one.html.

14. Fox J, Vendemia MA. Selective Self-Presentation and Social Comparison Through Photographs on Social Networking Sites. Cyberpsychol Behav Soc Netw 2016;19:593-600. 